\title{
Gestão integrada da Barragem Algodões II, Município de Curimatá, Estado do Piauí, Nordeste do Brasil
}

\section{Lorrane de Castro Miranda, Kássia Hellem Tavares da Silva, Luana de Castro Pereira* e Israel Lobato Rocha}

Instituto Federal do Piauí. Rua 6. Nova Corrente. Corrente-PI, Brasil. (CEP 64980-000).*E-mail: luannapereira.c@gmail.com.

Resumo. Este estudo objetivou fazer a caracterização da Barragem Algodões II, localizada no Município de Curimatá, Estado do Piauí, Nordeste do Brasil, dando ênfase aos municípios que compõe a Bacia do Rio Curimatá, na qual ela se insere. A área de estudos compreende três municípios nos quais a Barragem de Algodões II possui área de abrangência, considerando principalmente o Município de Curimatá. O levantamento dos dados foi feito através de informações disponíveis no Sistema de Acompanhamento de Reservatórios (SAR), o Sistema Nacional de Informações sobre Recursos Hídricos (SNIRH), coordenados pela Agência Nacional de Águas (ANA). Utilizaram-se ferramentas do Google Earth e Sistema de Informações Geográficas (SIG) Quantum GIS, quer para a caracterização da barragem, quer para a elaboração uma sequência histórica de imagens de satélites para mostrar as alterações que ocorreram na região da barragem, bem como as ocasionadas pela instalação do reservatório. Concluída em 2005, por meio de parceria do governo do estado com a Companhia de Desenvolvimento do Estado do Piauí (COMDEPI), a barragem está na unidade de gestão Parnaíba 03, com $52.297 \mathrm{~km}^{2}$, que compreende toda a área de drenagem do Rio Gurgueia. Nesta região, há predominância de áreas agrícolas, tornado as águas vulneráveis à ocorrência de contaminação por defensivos agrícolas. Neste caso, podem ser necessário o monitoramento e intervenções nessas ocorrências. A região passa por grandes períodos de estiagem, tornado o reservatório essencial para o abastecimento dos municípios circunvizinhos.

Palavras-chave: Bacia hidrográfica; Recursos hídricos; Sub-bacia do Curimatá.

\begin{abstract}
Integrated management of the Algodões II Dam, Curimatá Municipality, Piauí State, Northeast Brazil. This study aimed to characterize the Algodões II Dam, located in the County of Curimatá, Piauí State, Northeast Brazil. Emphasizing the munitions that make up the Curimatá River Basin. The study area comprises three municipalities in which the Algodões Dam II has its coverage areas, as well as data from the corresponding basin, mainly considering the Municipality of Curimatá. Data
\end{abstract}

Recebido: $18 / 12 / 2018$

Aceito:

$21 / 04 / 2019$

Publicado: 30/04/2019

Acesso aberto

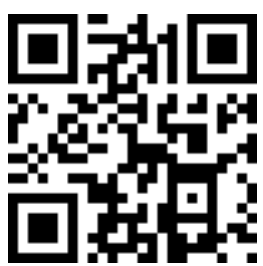

ORCID

(ㄷ) 0000-0002-3934-7779

Lorrane de Castro

Miranda

(ㄱ) $0000-0003-3148-1970$

Kássia Hellem Tavares da Silva

(D) 0000-0001-8814-0478

Luana de Castro

Pereira

D 0000-0002-4496-9935

Israel Lobato Rocha 
collection was done through information available in the Reservoir Monitoring System (SAR), the National System of Information on Water Resources (SNIRH), systems coordinated by the National Water Agency (ANA), Google Earth tools and GIS Quantum. Completed in 2005 through the state government in partnership with the Development Company of the State of Piauí (COMDEPI). The dam is in a management unit Parnaíba 03, with $52.297 \mathrm{~km}^{2}$, which comprises the entire drainage area of the Gurgueia River. A river historical sequence of satellite images shows the changes that occurred in the dam region, as well as the changes caused by the installation of the reservoir, with the predominance of agricultural areas, making the region vulnerable to the occurrence of contamination by agricultural pesticides. In addition, this practice can lead to problems of land use and occupation. Being a monitoring and interventions in these occurrences. The region goes through great periods of drought, becoming the reservoir essential for the supply of the surrounding municipalities.

Keywords: River basin; Water resources; Sub-basin of Curimatá.

\section{Introdução}

A Região Nordeste do Brasil apresenta regimes irregulares de precipitação em relação às outras regiões do país. Essa característica aliada a sua situação hidrológica, temperaturas elevadas durante todo ano, forte insolação e altas taxas de evapotranspiração, auxiliam na redução de sua disponibilidade hídrica, provocando consequências sociais e econômicas (ANA, 2016a).

Segundo a ANA (2016a), foram implementadas práticas para garantir a oferta de água na região Nordeste, tais como a construção de açudes. Estes auxiliam na gestão de recursos hídricos pela capacidade de estocar e atender a diversos usos da água, sejam eles consultivos ou não. Estes reservatórios colaboram para o armazenamento de água, nos períodos chuvosos, e distribuição nos períodos de estiagem.

A Região Hidrográfica do Parnaíba é considerada a segunda mais importante da Região Nordeste do Brasil. Ocupa uma área aproximada de 333.056 $\mathrm{km}^{2}$, o equivalente a $3,9 \%$ do território nacional, drena a quase totalidade do Estado do Piauí (99\%), parte do
Maranhão (19\%) e do Ceará (10\%). Os principais afluentes do Rio Parnaíba são o Rio das Balsas, situado no Estado do Maranhão, Rio Poti e Rio Portinho, cujas nascentes localizam-se no Estado do Ceará, e Rio Canindé, Rio Piauí, Rio Uruçui-Preto, Rio Gurgueia e Rio Longa, todos no Estado do Piauí (Lins e Andrade, 1975 ANA, 2016c).

Os maiores afluentes da margem direita do Rio Gurgueia são os Rios Santana e Curimatá. Por sua vez os afluentes que compõem a Bacia do Curimatá são o Riacho da Cruz, o Riacho da Areia, o Riacho Rangel e o Riacho do Angical, que possuem área de drenagem de aproximadamente $1.254 \mathrm{~km}^{2}$ e está situado na região sul do Estado do Piauí, bacia na qual está localizada a área de estudos (Barragem Algodões II) (Freitas et al., 1998).

0 empreendimento tem função fundamental para o abastecimento do Município de Curimatá e seus vizinhos, Júlio Borges e Avelino Lopes. Este último, segundo a Agência Nacional de Águas (ANA), é o único que apresenta pedido de outorga de direito de uso recursos hídricos na Bacia do Rio Parnaíba até o final de 2016. Este instrumento é 
essencial para o controle do uso desse recurso.

A Barragem de Algodões II tem uso prioritário para o abastecimento humano, entretanto, cabe destacar outros usos importantes, que pode ser destinado este recurso, tais como dessedentação de animais, lazer, irrigação e possível função de amortecimento de cheias decorrentes de chuvas intensas.

A ANA, em conjunto com os estados, estão responsáveis pela realização do monitoramento dos reservatórios do Nordeste, acompanhando os volumes de águas disponíveis em 280 reservatórios, que apresentam capacidade igual ou superior a $10 \mathrm{hm}^{3}$ (ANA, 2016a). Em fevereiro de 2017, estavam cadastrados 508 reservatórios no Nordeste, com volumes entre 0,054 a $6.700 \mathrm{hm}^{3}$.

Entretanto, observou-se, na elaboração deste estudo, a carência de informações sobre o empreendimento, sobre tudo, dados da bacia que o abastece. Essas informações sobre usos, demandas, vazão, características físicas hidráulicas, hidrológicas, têm importância vital para auxiliar a gestão adequada dos recursos hídricos da bacia. Essa gestão garantiria a oferta de água a todos, direito este assegurado pela Política Nacional de Recursos Hídricos, instituída pela Lei no 9.433/1997 (Brasil, 1997).

Diante do exposto, o estudo objetivou fazer a caracterização da Barragem Algodões II, localizada no Município de Curimatá, Estado do Piauí, Nordeste do Brasil, e da bacia na qual se insere, objetivando subsidiar a melhoria da gestão deste empreendimento.

\section{Material e métodos}

\section{Áreas de estudo}

0 foco dos estudos compreende a Barragem de Algodões II e os três municípios nos quais possui áreas de abrangência, bem como dados da bacia correspondente, considerando principal- mente o Município de Curimatá, que está localizado no extremo sul do Estado do Piauí, com população aproximada de 10.761 pessoas, área territorial de 2.337.537 $\mathrm{km}^{2}$, estando inserido nos biomas Cerrado e Caatinga (IBGE, 2010), possuindo clima tropical semiárido quente, com duração do período seco de seis meses.

O Estado do Piauí possui um total de 25 reservatórios. A Barragem de Algodões II está localizada nos Municípios Curimatá e Júlio Borges, mas foi construída com o objetivo de abastecer os Municípios de Curimatá, Júlio, Avelino Lopes e Morro Cabeça no Tempo. A barragem tem a capacidade de armazenar o equivalente a 247.000.000 $\mathrm{m} / \mathrm{s}$ de água, o que a torna a terceira maior barragem do Estado do Piauí, possui uma lamina d'água de $35 \mathrm{~m}$ de altura, no eixo do maciço da barragem, e o comprimento longitudinal de seu reservatório mede mais de $37 \mathrm{~km}$ (Piauí, 2010).

A sua construção foi concluída em 2005, pelo Governo do Estado do Piauí, em parceria com a Companhia de Desenvolvimento do Estado do Piauí (COMDEPI). A barragem está na unidade de gestão Parnaíba 03, com $52.297 \mathrm{~km}^{2}$, que compreende toda a área de drenagem do Rio Gurgueia, que tem como afluente o Rio Paraim, que tem como afluente o Rio Curimatá (Piauí, 2010) (Figura 1).

\section{Procedimentos metodológicos}

O levantamento dos dados da Barragem Algodões II, foi feito através de informações disponíveis no Sistema de Acompanhamento de Reservatórios (SAR), consulta a especialistas e visita a órgãos públicos.

O SAR contempla dados e informações dos reservatórios. Disponibiliza informações sobre açudes, espacialização da informação e análises da operação dos reservatórios. É mantido e administrado pela Coordenação de Acompanhamento de Reservatório e Sistemas Hídricos (CORSH) da 
Superintendência de Operações e Eventos Críticos (SOE), da ANA (ANA, 2018).

0 outro instrumento utilizado para aquisição de dados é o SNIRH. Instrumento de gestão previstos na Política Nacional de Recursos Hídricos, instituída pela Lei no 9.433/1997 (Brasil, 1997), é uma ferramenta com aptidão para coleta, tratamento, armazenamento e recuperação de informações sobre recursos hídricos, bem como fatores intervenientes para sua gestão.

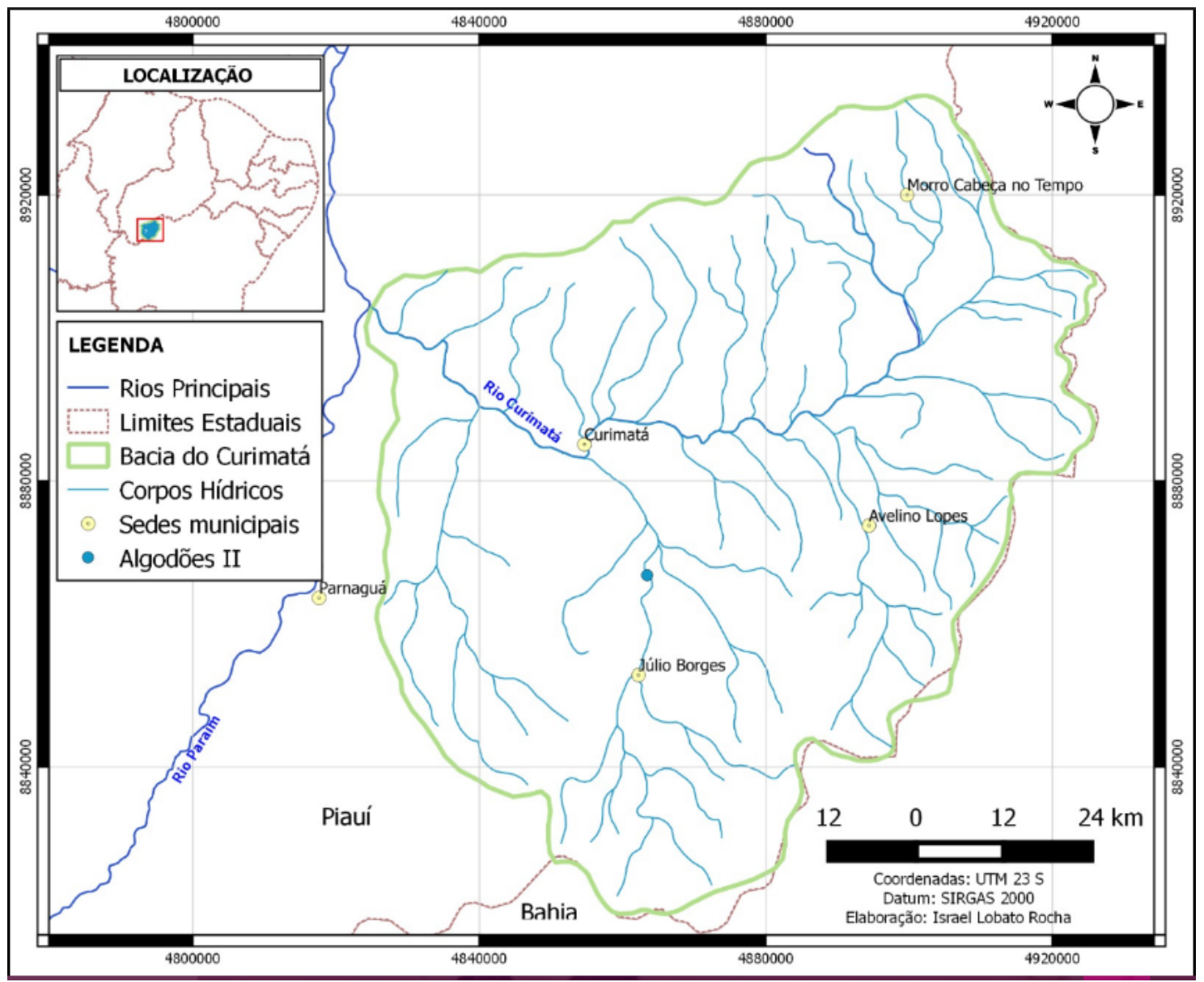

Figura 1. Mapa de localização da área de estudo.

Muitas das características de Algodões II não foram encontradas nos bancos de dados dos organismos governamentais. Assim, buscou-se definilas por meio do uso de ferramentas do Google Earth e do Sistema de Informações Geográficas (SIG) Quantum GIS. Utilizando-se dessa tecnologia como forma alternativa para a gestão ambiental. Portanto, utilização de metodologia remota para a caracterização física do reservatório.

Assim, além das imagens, utilizaram-se outras ferramentas disponibilizadas no Google Earth, série históricas de imagens, "caminho", "perfil de elevação" e "régua" de modo a fazer a caracterização preliminar das características físicas da barragem e de seu entorno. Para tanto, traçou-se um 
"caminho" (segmento de reta/curva) transversal à barragem. Uma vez traçado o segmento de reta/curva, criou-se o perfil de elevação. Por meio deste perfil buscou-se identificar a elevação do pé da barragem e de sua crista, bem como a distância entre eles. Obtidas estas informações, calculou-se a declividade do talude de jusante do barramento. A régua permitiu estimar a extensão da crista do barramento, das ombreiras.

Considera-se que o método pode ser aplicável em estudos em que não se dispõe de documentos com dados e nem de acesso ao empreendimento. A metodologia foi proposta conforme notas técnicas sobre barragens de mineração no Brasil (ANA, 2016b), resultando na elaboração de nota técnica sobre barragens de mineração na Amazônia e na produção de um documento com sugestões de gestão desses empreendimentos. A metodologia, no entanto, precisa ser validada em campo ou com dados de projeto, para conferir maior confiabilidade à informação gerada.

Para obtenção dos resultados de declividade da barragem utilizou-se da seguinte equação:

\section{Declividade = (nível da crista da barragem - nível do pé da barragem) Tamanho do segmento}

As imagens utilizadas, nesta metodologia, são aquelas do Google Earth, de 2016. Altura do ponto de visão $7,59 \mathrm{~km}$. As imagens não passaram por nenhum tipo de tratamento para a obtenção dos parâmetros físicos da barragem. A ideia é a aplicação de uma metodologia simples e remota aplicável à gestão.

De posse dos resultados, pode-se identificar características da barragem, tais como: dados físicos, hidrológicos e seus usos. Dados de vulnerabilidade da bacia do rio Curimatá, pontos positivos e negativos da implantação da barragem foram levantados para melhor caracterizá-la.

\section{Resultados e discussão}

A Bacia do Rio Curimatá é uma das mais importantes do Rio Gurgueia. A implantação deste reservatório se faz relevante por se tratar de uma região que passa por grades períodos de estiagem e seus reservatórios subterrâneos não suprem a necessidade de água da população desta região, além de não apresentarem qualidade adequada para o consumo, segundo dados da Secretária Nacional de Defesa Civil, que dispõe de um levantamento de Reconhecimento de Estado de Situação de Emergência (SE) e Estado de Calamidade Pública (ECP) realizados em 2014 no Piauí.

Entre os anos de 2003 a 2016, foram reconhecidos dez eventos de SE na região da barragem, caracterizados como: oito estiagens e dois de seca. Os eventos de seca forma registrados nos anos de 2003 e 2010, Tabela 1. Esse levantamento mostra a vulnerabilidade da região com relação à falta de água, tornando o Açude de Algodões II um importante instrumento para a gestão deste recurso.

Na Tabela 1, pode-se observar que, no ano de 2013, no município de Curimatá, foram reconhecidos três eventos, todos são considerados SE. Este foi ano de maior ocorrência. Percebe-se que, entre os anos de 2013 a 2016, ocorreram oito SE. Após 2012, anualmente, houve ocorrência desses eventos.

Neste mesmo levantamento, a cidade de Júlio Borges tem destaque entre as cidades da bacia do Curimatá, com 11 SE decretados, entre os anos de 2003 e 2015. Em 2003, 2005 e 2010 identificou-se seca no município (Tabela 2). 
Tabela 1. Ocorrências de secas e estiagem registradas na região da barragem.

\begin{tabular}{|l|c|c|c|c|}
\hline Ano & Evento & Estado & Data & Frequência \\
\hline $\mathbf{2 0 0 3}$ & Seca & SE* & $17 / 11 / 2003$ & 1 \\
\hline $\mathbf{2 0 0 7}$ & Estiagem & SE & $03 / 10 / 2007$ & 1 \\
\hline $\mathbf{2 0 1 0}$ & Seca & SE & $21 / 06 / 2010$ & 1 \\
\hline $\mathbf{2 0 1 2}$ & Estiagem & SE & $16 / 04 / 2012$ & 1 \\
\hline \multirow{3}{*}{$\mathbf{2 0 1 3}$} & Estiagem & SE & $15 / 02 / 2013$ & 1 \\
\cline { 2 - 5 } & Estiagem & SE & $13 / 06 / 2013$ & 1 \\
\cline { 2 - 5 } & Estiagem & SE & $20 / 12 / 2013$ & 1 \\
\hline $\mathbf{2 0 1 4}$ & Estiagem & SE & $09 / 06 / 2014$ & 1 \\
\hline $\mathbf{2 0 1 5}$ & Estiagem & SE & $13 / 03 / 2015$ & 1 \\
\hline $\mathbf{2 0 1 5}$ & Estiagem & SE & $21 / 07 / 2015$ & 1 \\
\hline $\mathbf{2 0 1 6}$ & Estiagem & SE & $25 / 02 / 2016$ & 1 \\
\cline { 2 - 5 } & Estiagem & SE & $13 / 09 / 2016$ & 1 \\
\hline
\end{tabular}

*Situação de emergência Fonte: Secretária Nacional de Defesa Civil

A Tabela 2 mostra que no ano de 2013 verificou-se a ocorrência dos eventos de SE na mesma proporção. No entanto, há episódio de chuvas intensas no ano 2004 no mês de abril. Do mesmo modo, a partir de 2012, esses acontecimentos foram frequentes a cada ano.

Tabela 2. Ocorrências de secas e estiagem registradas na região da barragem.

\begin{tabular}{|l|c|c|c|c|}
\hline Ano & Evento & Estado & Data & Frequência \\
\hline $\mathbf{2 0 0 3}$ & Seca & SE* & $20 / 11 / 2003$ & 1 \\
\hline $\mathbf{2 0 0 4}$ & Chuvas intensas & SE & $24 / 03 / 2004$ & 1 \\
\hline $\mathbf{2 0 0 5}$ & Seca & SE & $29 / 09 / 2005$ & 1 \\
\hline $\mathbf{2 0 0 7}$ & Estiagem & SE & $14 / 12 / 2007$ & 1 \\
\hline $\mathbf{2 0 1 0}$ & Seca & SE & $26 / 05 / 2010$ & 1 \\
\hline $\mathbf{2 0 1 2}$ & Estiagem & SE & $11 / 05 / 2012$ & 1 \\
\hline $\mathbf{2 0 1 3}$ & Estiagem & SE & $15 / 02 / 2013$ & 1 \\
\cline { 2 - 5 } & Estiagem & SE & $13 / 06 / 2013$ & 1 \\
\cline { 2 - 5 } & Estiagem & SE & $20 / 12 / 2013$ & 1 \\
\hline $\mathbf{2 0 1 4}$ & Estiagem & SE & $09 / 06 / 2014$ & 1 \\
\hline $\mathbf{2 0 1 5}$ & Estiagem & SE & $13 / 03 / 2015$ & 1 \\
\cline { 2 - 5 } & Estiagem & SE & $21 / 07 / 2015$ & 1 \\
\hline $\mathbf{2 0 1 6}$ & Estiagem & SE & $25 / 02 / 2016$ & 1 \\
\cline { 2 - 5 } & Estiagem & SE & $13 / 09 / 2016$ & \\
\hline
\end{tabular}

*Situação de emergência Fonte: Secretária Nacional de Defesa Civil

Por sua vez, o açude apresentou uma variação percentual de volume significativa, em levantamento dos anos de 2005 a 2016. Nota-se que os registros de menores volumes do reservatório ocorreram nos meses de dezembro. Este resultado pode estar associado ao baixo nível pluviométrico desse período do ano, que se caracteriza como seco.
Quando se trata de volume anual, o ano de menor registrofoi2008, mais precisamente, no mês de janeiro, com valor mínimo acumulado de $14 \mathrm{~m}^{3}$, o equivalente a $5,67 \%$ de sua capacidade. Entretanto, neste ano,no mês seis houve aumento expressivo com os valores de $140 \mathrm{~m}^{3}, 56,68 \%$ total (Figura 2). 


\section{Volume Percentual 2008}

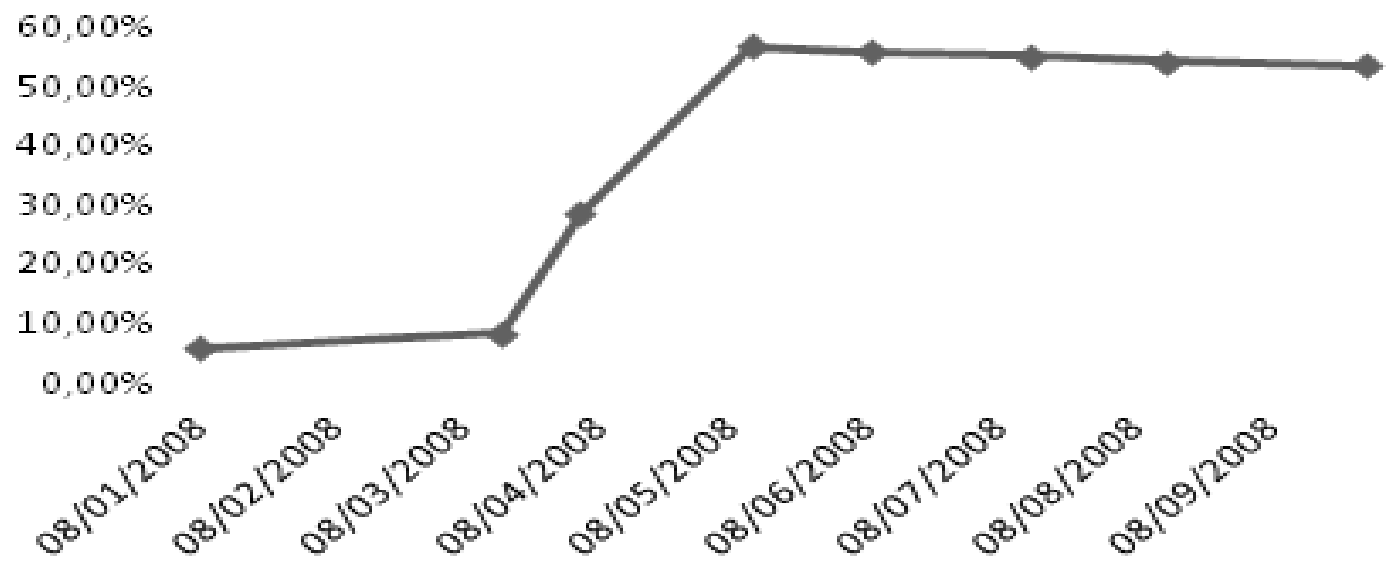

Figura 2. Percentual de volume do açude em 2008. Fonte: SAR.

0 ano de maior volume foi 2011 , com valor de $160 \mathrm{~m}^{3}$, um total de $64,78 \%$ de sua capacidade, mostrando um volume expressivo neste ano (Figura 4). Neste ano, melhorias foram registradas nos índices pluviométricos de acordo o que mostra o volume percentual deste ano, podendo os resultados de volume elevado apresentados na Figura 3 estarem associados ao melhoramento de precipitação pluviométricas do ano correspondente.

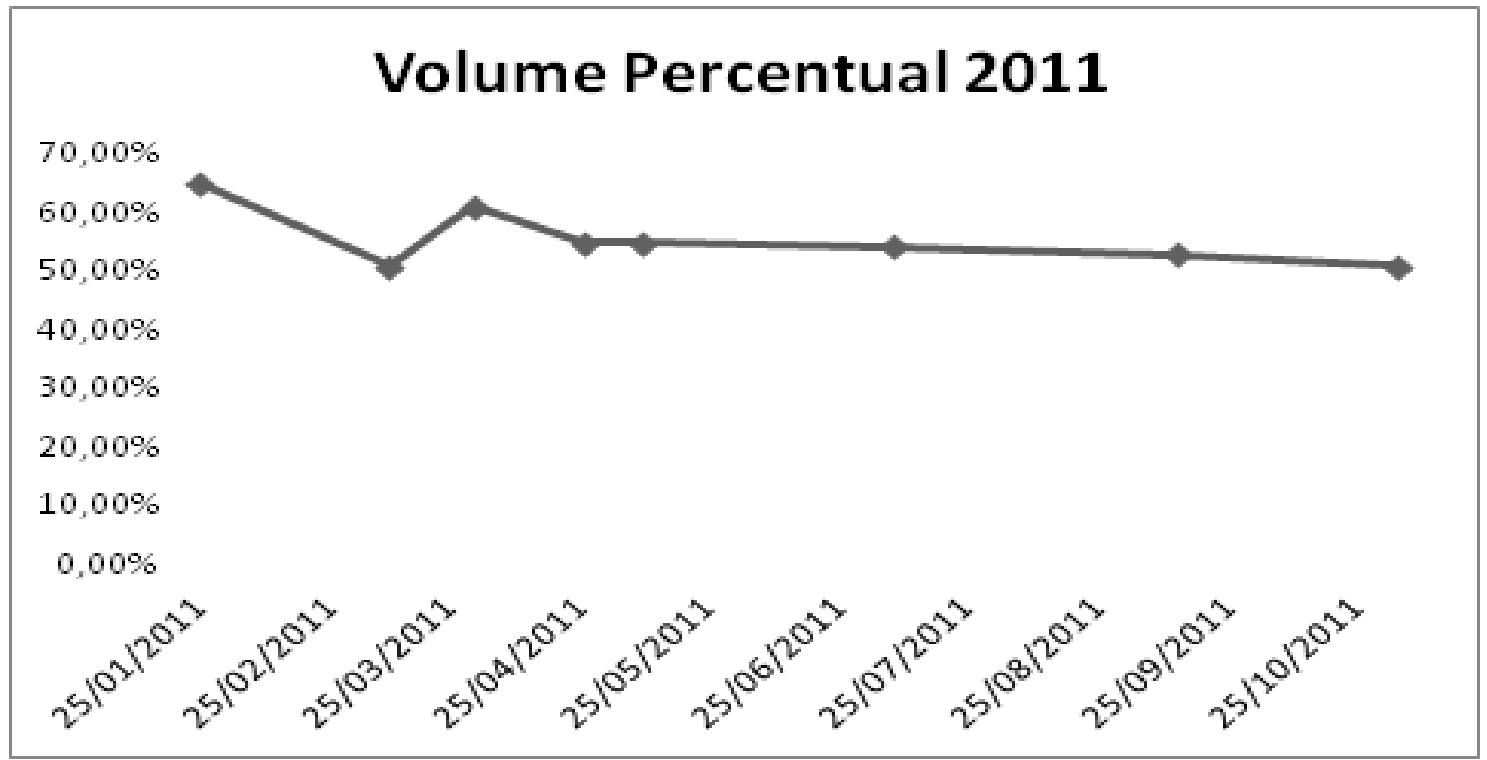

Figura 3. Percentual de volume do açude em 2011. Fonte: SAR. 
Segundo o Boletim de Informações Climáticas do Piauí, em novembro e outubro de 2015, observaram-se chuvas abaixo da média histórica no Piauí. Maiores desvios foram verificados no sul, onde a maiorias dos municípios não apresentaram eventos de chuva significativo. Mostrando uma queda brusca dos volumes de água armazenada no reservatório em estudo, indicando a importância de um plano de gestão da bacia do rio Curimatá, para evitar problemas futuros de escassez.

Cabe ressaltar que, para seleção dos dados obtidos, sobre os volumes do açude, através do SAR, foi levado em consideração o ano de sua inauguração, 2005. Observou-se que, a partir do ano de 2011, o reservatório não apresentou volume acima de $50 \%$ (Figura 4).

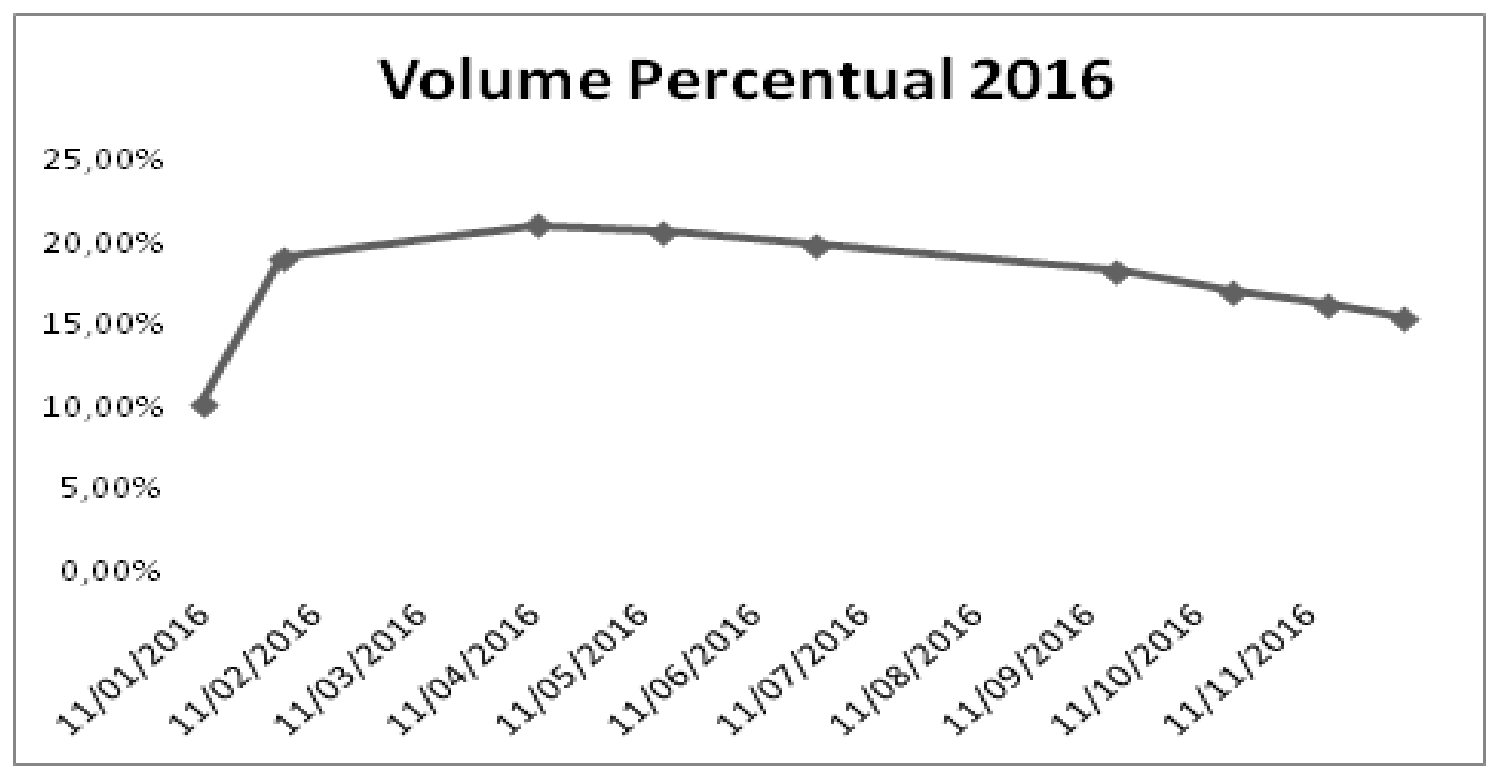

Figura 4. Percentual de volume do açude, em 2016. Fonte: SAR.

Com exceção de 2008, nos demais anos os volumes do Reservatório Algodões II têm uma variação semelhante em seu percentual de volume, nos meses de janeiro a março, ocorre um aumento do volume armazenado, no corpo hídrico em estudo, o que pode estar associado ao período chuvoso da região que ocorre nessa temporada. Havendo um decréscimo do volume, no segundo semestre, por se tratar do período seco.

Com o conhecimento desse período de menor volume, pode-se propor políticas objetivando a conservação deste recurso, na tentativa de evitar que o reservatório seque. Cabe levar em consideração os usos em toda a bacia, com enfatize na cidade de Júlio Borges, que fica à montante do reservatório.

\section{Características físicas do reservatório e da área em torno}

As características físicas de uma barragem permitem a definição de sua capacidade (volume), portanto de seu aproveitamento. São importantes, ainda, para a avaliação do risco associado a ela (Lei de Segurança de Barragens) etc. Entre estas características, encontra-se a altura da barragem, isto é, a distância vertical entre a superfície do terreno que recebe a barragem e a superfície da água 
no reservatório, por ocasião da ocorrência da vazão máxima de projeto do extravasor, acrescida de uma borda livre ou folga.

Outro aspecto verificado foi a evolução da região, após a construção da barragem. A sequência histórica de imagens de satélites mostra as alterações que ocorreram na região da barragem, bem como as alterações ocasionadas pela instalação do reservatório.
A projeção mostra o aumento da lamina d'água, na área da barragem. Nota-se expansão da área agrícola nas margens do reservatório. Isso pode estar associado à disponibilidade hídrica, para o uso da irrigação.

Conforme se identifica, essas áreas tendem a crescer. Isso pode influenciar na alteração do uso e ocupação do solo (Figura 5).

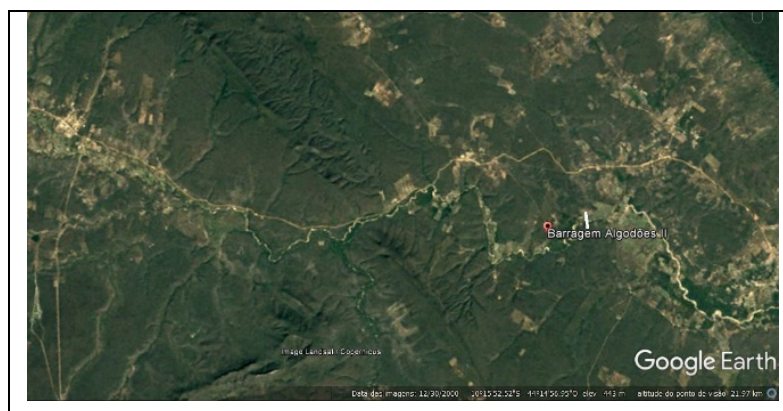

2000

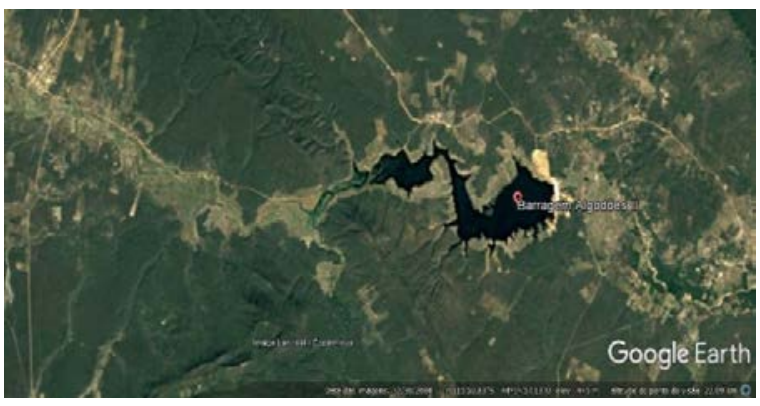

2004

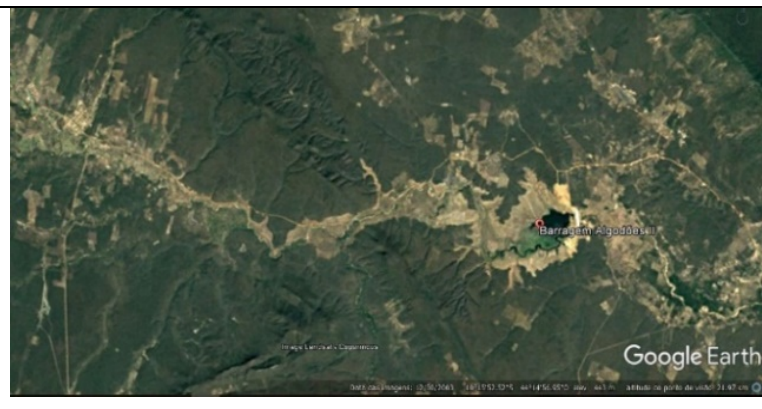

2003

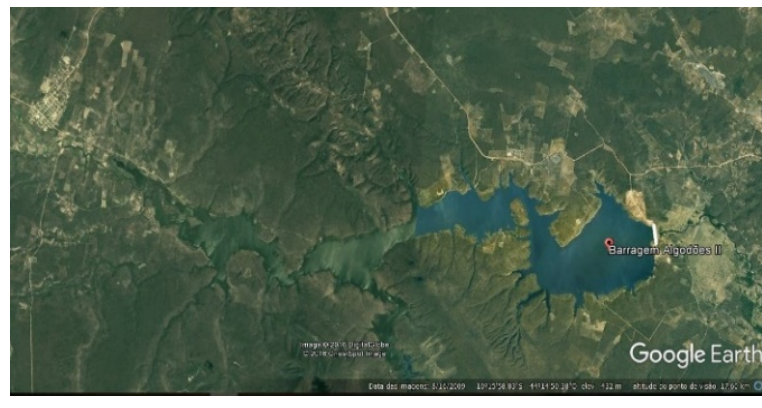

2009

Figura 5. Sequência histórica da área de estudos. Fonte: Google Earth.

\section{Considerações finais}

Nota-se que o Algodões II têm grande potencial de reservação e a região, onde se localiza, passa por expressivos períodos de estiagem. Mas como mostraram as imagens de satélite analisadas, esta região vem passando por diversas transformações físicas. Isso se dá, segundo análise das imagens, por se identificar o uso agrícola próximo as margens do reservatório. Cabendo diante disto, monitorar e estabelecer políticas de intervenção desta atividade para prevenir contra degradação da área e a contaminação do corpo hídrico por defensivos agrícolas.

A região passa por grandes períodos de estiagem, tornado o reservatório essencial para o 
abastecimento dos municípios circunvizinhos. Caberia um plano de gestão para esta bacia na tentativa de evitar uma situação de escassez futuramente.

\section{Conflitos de interesse}

Os autores declaram não haver conflitos de interesse.

\section{Referências}

ANA - Agência Nacional de Águas. Conjuntura dos recursos hídricos: Informe 2016. Brasília: ANA, 2016a.

ANA - Agência Nacional de Águas. Relatório de segurança de barragens 2015. Brasília: ANA, 2016b.

ANA - Agência Nacional de Águas. Região Hidrográfica do Parnaíba. Brasília: ANA, 2016c. Disponível em: <http://www2.ana. gov.br/Paginas/portais/bacias/Parnaiba.asp $\mathrm{x}>$. Acesso em: 17 set. 2018.

ANA - Agência Nacional de Águas. SAR Sistema de Acompanhamento de Reservatórios. 2018. Disponível em: <http://sar.ana.gov.br/Home/About>. Acesso em: 17 set. 2018.
Brasil. Lei no 9.433, de 8 de janeiro de 1997. Institui a Política Nacional de Recursos Hídricos, cria o Sistema Nacional de Gerenciamento de Recursos Hídricos, regulamenta o inciso XIX do art. 21 da Constituição Federal, e altera o art. 10 da Lei no 8.001, de 13 de março de 1990, que modificou a Lei no 7.990 , de 28 de dezembro de $1989 . \quad$ Disponível em: <http://www.planalto.gov.br/ccivil_03/LEIS /L9433.htm>. Acesso em: 01 set. 2018.

Freitas, M. A. S.; Marwell Filho, P.; Nunes, C. N. A gestão integrada dos recursos hídricos no Estado do Piauí. Anais do IV Simpósio de Recursos Hídricos do Nordeste, 1998.

IBGE - Instituto Brasileiro de Geografia e Estatística. Censo demográfico 2010. Disponível em: <http://www.cidades.ibge. gov.br/>. Acesso em: 01 set. 2018.

Lins, R. C.; Andrade, G. O. Aspectos hidrográficos da Bacia do Parnaíba. Ciência \& Trópico, v. 3, n. 2, p. 121-136, 1975.

Piauí. Plano Estadual de Recursos Hídricos do Estado do Piauí: Relatório síntese. Teresina: Secretário de Estado do Meio Ambiente e Recursos Hídricos, 2010. 